\title{
Patient satisfaction with health care services provided at HIV clinics at Amana and Muhimbili hospitals in Dar es Salaam
}

\author{
*Kagashe GAB, Rwebangila F \\ School of Pharmacy, Muhimbili University of Health and Allied Sciences, Dar es Salaam
}

\begin{abstract}
Background: Since the establishment of free HIV/AIDS care and treatment services in Tanzania a lot of research has been done to assess how health care providers discharge their duties in these clinics. Little research however has been done regarding satisfaction of HIV patients with free health care services provided.

Objectives: 'To determine satisfaction of HIV patients with health care services provided at the HIV clinics and specifically, to determine patients' satisfaction with the general physical environment of the clinic and with services offered by doctors, nurses, laboratory, and pharmacy.

Methods: A cross-sectional study was conducted at Muhimbili National Hospital (MNH) and Amana hospital. A total of 375 patients attending outpatient HIV clinics were selected randomly and interviewed using a questionnaire, after obtaining a verbal consent. Data collected was analyzed using Epi-info program version 6.

Results: Patients at Amana Hospital clinic were either very satisfied (44.3\%) or satisfied (55.7\%) and none were unsatisfied, while at MNH clinic 1.1\% patients were very satisfied while $(94.7 \%)$ were satisfied and $(4.2 \%)$ were unsatisfied with health care services provided. Lack of privacy when consulting with doctors and the dispenser contributed to patients' unsatisfaction with the services.

Conclusion: Most of the participants were satisfied with the services provided at the two clinics. However at MNH, a few patients were unsatisfied due to lack of privacy during consultation with doctors and with the pharmacy services.
\end{abstract}

Key words: Patient satisfaction, Antiretroviral therapy, HIV care services

African Health Sciences 2011; 11(S1): S60 - S66

\section{Introduction}

The government of Tanzania in 2004 established HIV clinics that provide free health care and treatment to HIV patients. Providing antiretroviral (ARV) therapy requires skilled personnel to handle the HIV patient as well as antiretroviral medicines. Training of health workers was therefore conducted and is still going on. Since then several studies have been carried out to evaluate providers' ability in these HIV care and treatment clinics. ${ }^{1,2}$ However, only a few studies have assessed if HIV-patients are satisfied with the health care services provided at these clinics. ${ }^{3,4}$

Patient satisfaction has been defined as the patient's "Personal evaluation of providers' ability

*Correspondence author
Dr. Godeliver A.B. Kagashe
Deparment of Pharmaceutics
School of Pharmacy
Muhimbili University of Health and Allied Sciences
P.O. Box 65577
Dar es Salaam
Tel 255713310511
E-mail: gkagashe@,muhas.ac.tz

of health care services". It reflects provider's ability to successfully deliver care that meets patients' expectations and needs. ${ }^{5,6} \mathrm{~A}$ number of factors have been shown to influence patients' satisfaction with health care services including patients' sociodemographic characters, physical health status, patients' personal understanding and expectations from various health care services i.e. doctors, nurses, laboratory and pharmacy services. ${ }^{7,8,9}$ The general physical appearance of the clinic as well as the general environment of the premises also influences the overall satisfaction of the patient. ${ }^{10}$ Length of waiting time before seeing the doctor has also been shown to influence patient satisfaction. ${ }^{11}$

The objective of this study was therefore to assess if HIV-patients are satisfied with health care services provided by doctors, nurses, laboratory technicians, and pharmaceutical personnel at HIV care and treatment clinics situated at Amana hospital and Muhimbili National Hospital. In addition the study assessed patients' satisfaction with the physical environment and cleanliness of the clinics. 


\section{Methods}

This was a cross-sectional study conducted at $\mathrm{MNH}$ and Amana Hospital HIV clinics. The study involved 375 adult HIV patients attending the clinics and who were already on ARV therapy. Patients were selected randomly, with 190 patients from MNH clinic and 185 patients from Amana clinic. Children, inpatients, and those patients attending the clinics but not yet on ARV therapy, were excluded from the study. Patient's satisfaction with doctor's services, pharmacy services, nurses and laboratory services was assessed. Satisfaction with the general physical environment of the premises of the HIV clinic was also assessed. Ethical clearance was obtained from MUHAS Ethical Review Committee. Letters requesting permission to conduct the study at the clinics were sent to the respective hospitals. After obtaining permission, the researcher visited the clinics and collected data by interviewing patients. Patients were given a short introduction to the study and told the purpose of the study. They were assured that the information given would be kept confidential. They were then asked verbally whether they were willing to participate or not. Those who agreed were then interviewed.

\section{Data collection and analysis}

Data was collected using a pretested questionnaire by interviewing patients who consented. The questionnaire was made up of open ended and closed ended questions aiming at assessing the services offered. The questionnaire was pretested among 30 patients and then modified accordingly. Data was analyzed using Epi-info version 6 program; Frequencies and percentages scoring from 0 to $100 \%$ were calculated with high scores indicating higher levels of patients' satisfaction.

\section{Results}

Table 1 shows demographic features of 375 participants interviewed. Most people were between 31 to 35 yeals $(34.4 \%)$. About two thirds were women $(63.8 \%)$. All participants had been attending the clinics for more than a year.
Table 1: Patients socio-demographic variables

\begin{tabular}{llc}
\hline $\begin{array}{l}\text { Main } \\
\text { variable }\end{array}$ & $\begin{array}{l}\text { Specific } \\
\text { variable }\end{array}$ & $\begin{array}{c}\text { Percentage } \\
\text { distribution } \\
\text { (n=375) }\end{array}$ \\
\hline Sex & Men & 36.2 \\
Age & Women & 63.8 \\
& Less than 30 years 13.3 \\
& $31-35$ years & 34.4 \\
& $36-44$ years & 29.6 \\
Marital status & More than 45 years & 26.7 \\
& Married & 44.5 \\
& Not married & 22.4 \\
& Divorced & 21.9 \\
Education level & Widowed & 11.2 \\
& Primary & 24.0 \\
& Secondary & 44.8 \\
& Diploma/degree & 18.4 \\
& Not educated & 12.8 \\
Employment status & & \\
& Full-time employed & 20.3 \\
& Part-time employed & 11.3 \\
& Self employed & 47.2 \\
& Unemployed & 20.3 \\
Health status & Very good & 20.5 \\
& Improving well & 66.9 \\
& Poor & 12.5 \\
\hline
\end{tabular}

Table 2 shows factors related to satisfaction with doctors' services. The majority of the patients had to wait for more than one hour for consultation as indicated by $71.6 \%$ for $\mathrm{MNH}$ and $77.3 \%$ for Amana Hospital. At MNH majority of patients (81.6\%) had no privacy during consultation with the doctor compared to only 3.8\% at Amana as shown in figure 1. This difference was statistically significant at $\mathrm{p}<0.0001$ and $\mathrm{z}$ value \pm 15.1 . Consultation time was estimated to be 10 to 15 minutes by $77.9 \%$ of patients at $\mathrm{MNH}$ and by $55.1 \%$ at Amana hospital. 
Table 2: Patients' satisfaction with doctors' services

\begin{tabular}{llcc}
\hline Main Variable & Specific variables & $\begin{array}{c}\text { Muhimbili } \\
\text { Hospital } \\
\mathbf{n = 1 9 0} \mathbf{~ ( \% )}\end{array}$ & $\begin{array}{c}\text { Amana } \\
\text { Hospital } \\
\mathbf{n = 1 8 5} \mathbf{( \% )}\end{array}$ \\
\hline Availability of the Doctors at the clinic. & All times & 88.9 & 98.4 \\
& Not available & 1.6 & 0 \\
& Sometimes & 9.5 & 1.6 \\
Time taken waiting for consultation. & Less than 30 minutes & 1.1 & 0.5 \\
& 30 minutes to 1 hour & 27.4 & 21.6 \\
Estimated consultation time. & More than 1 hour & 71.6 & 77.3 \\
& 10 to 15 minutes & 77.9 & 55.1 \\
Patient's understanding of the & 16 to 20 minutes & 22.1 & 33.0 \\
doctor's counselling & More than 20 minutes & 0 & 11.9 \\
\multirow{3}{*}{ Privacy during consultation. } & Easy to understand & 86.3 & 96.8 \\
& Difficult to understand & 12.1 & 1.6 \\
Attitude of the doctors towards & Not sure & 1.6 & 1.6 \\
patients & Privacy & 18.4 & 96.2 \\
Satisfied with doctors' services & No privacy & 81.6 & 3.8 \\
& Friendly & 93.2 & 97.3 \\
& Unfriendly & 6.8 & 2.7 \\
& Very satisfied & 1.1 & 30.8 \\
& Satisfied & 95.3 & 69.2 \\
\hline
\end{tabular}

Figure 1: Privacy during consultation with the doctor

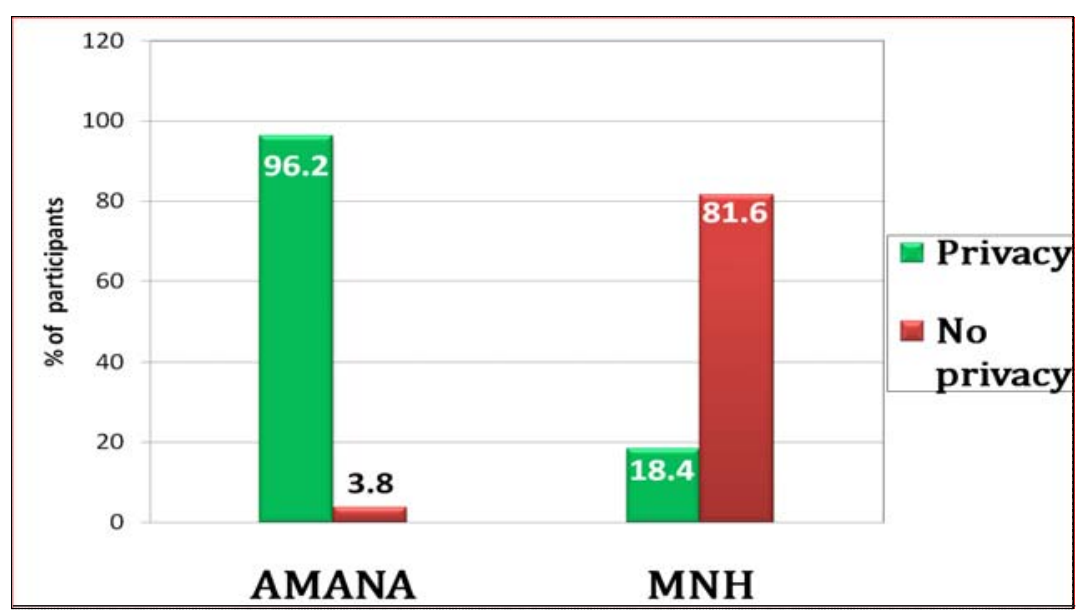

Pharmacy services for both clinics is indicated in table 3. Eighty three percent of the patents at $\mathrm{MNH}$ and $95.7 \%$ at Amana indicated that medicines were available. The time spent waiting for pharmacy services at Amana Hospital was less than 30 minutes for $67 \%$ of patients, while at $\mathrm{MNH}$ the majority of the patients $(98.9 \%)$ took from 30 minutes to one hour to get their medications from the pharmacy. 
Table 3: Patients' satisfaction with pharmacy services

\begin{tabular}{|c|c|c|c|}
\hline Main Variable & Specific variables & $\begin{array}{l}\text { Muhimbili } \\
\text { Hospital } n=190 \\
(\%)\end{array}$ & $\begin{array}{l}\text { Amana } \\
\text { Hospital } n=185 \\
(\%)\end{array}$ \\
\hline \multirow[t]{3}{*}{ Time spent waiting for pharmacy services } & Less than 30 minutes & 1.1 & 67.0 \\
\hline & 30 minutes to 1 hour & 98.9 & 33.0 \\
\hline & More than 1 hour & 0 & 0 \\
\hline \multirow[t]{4}{*}{ Drug availability in the pharmacy } & Available & 83.7 & 95.7 \\
\hline & Not available & 1.6 & 0 \\
\hline & Sometimes & 8.4 & 0 \\
\hline & Not sure & 6.3 & 3.2 \\
\hline \multirow[t]{3}{*}{ Dose counseling } & Counseled & 53.7 & 93.5 \\
\hline & Not often counseled & 37.9 & 6.5 \\
\hline & Not counseled at all. & 8.4 & 0 \\
\hline \multirow[t]{3}{*}{ ARV Side effects counseling } & Counseled & 22.6 & 93.5 \\
\hline & Not often counseled & 56.7 & 6.5 \\
\hline & Not counseled at all & 21.1 & 0 \\
\hline \multirow[t]{2}{*}{ Privacy with the dispensers } & Privacy & 9.5 & 98.4 \\
\hline & No privacy & 90.5 & 1.6 \\
\hline \multirow[t]{2}{*}{ Attitude of dispensers towards patients } & Friendly & 78.9 & 99.5 \\
\hline & Unfriendly & 21.1 & 0.5 \\
\hline \multirow[t]{3}{*}{ How satisfied with pharmacy services } & Very satisfied & 1.6 & 28.6 \\
\hline & Satisfied & 84.7 & 71.4 \\
\hline & Unsatisfied & 13.7 & 0 \\
\hline
\end{tabular}

At Amana 93.5\% of patients said they were counseled on the ARV side effects and all participants had privacv during dispensing of ARV medicines.

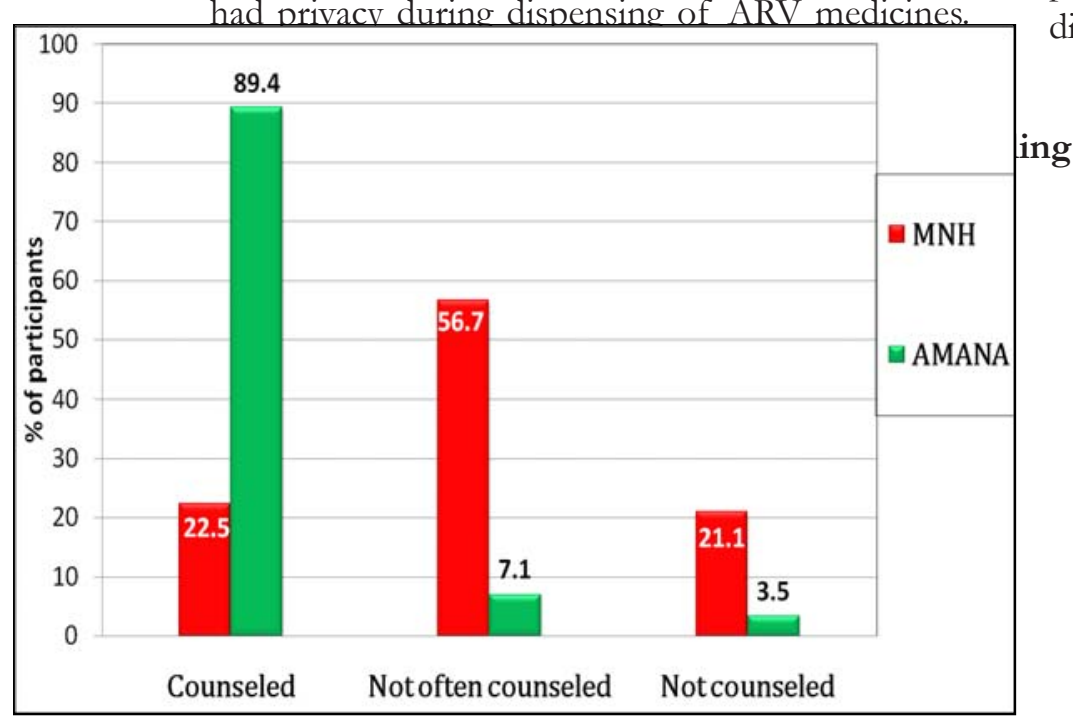

ARV side effects (Fig 2.) and the majority of participants $(90.5 \%)$ had no privacy with the dispensers.
In both clinics the majority of respondents said the number of nurses providing services was adequate. Nurses' attitude while providing services and the overall patient's satisfaction with the nurses' services are indicated in table 4. Only (5.8\%) of patients at $\mathrm{MNH}$ were unsatisfied with the laboratory services provided at the clinics, the rest of the results are indicated in table 4. 
Table 4: Patients' satisfaction with nurse and laboratory services

\begin{tabular}{|c|c|c|c|}
\hline \multirow[t]{2}{*}{ Main Variable } & \multirow[t]{2}{*}{ Specific variables } & \multicolumn{2}{|c|}{$\begin{array}{ll}\text { Muhimbili } & \text { Amana }\end{array}$} \\
\hline & & $\begin{array}{l}\text { Hospital } n=190 \\
(\%)\end{array}$ & $\begin{array}{l}\text { Hospital } n=185 \\
(\%)\end{array}$ \\
\hline \multicolumn{4}{|l|}{ Nurses } \\
\hline Number of nurses providing & Enough & 81.1 & 89.7 \\
\hline \multirow[t]{2}{*}{ services at the clinic } & Not enough & 0.5 & 1.1 \\
\hline & Not sure & 18.4 & 9.2 \\
\hline \multirow[t]{2}{*}{ Attitude towards patients } & Friendly & 95.3 & 100 \\
\hline & Unfriendly & 4.7 & 0 \\
\hline \multirow[t]{3}{*}{ How satisfied with nurse services } & Very satisfied & 2.1 & 35.7 \\
\hline & Satisfied & 95.3 & 64.3 \\
\hline & Unsatisfied & 2.6 & 0 \\
\hline \multicolumn{4}{|l|}{ Laboratory } \\
\hline Estimated time waiting for & Less than 30 minutes & 0.5 & 69.7 \\
\hline \multirow[t]{2}{*}{ Lab. test to be taken } & 30 minutes to 1 hour & 98.9 & 30.3 \\
\hline & More than 2 hours & 0.5 & 0 \\
\hline \multicolumn{4}{|c|}{ Attitude of the laboratory technicians towards patients } \\
\hline & Friendly & 91.1 & 100 \\
\hline & Unfriendly & 8.9 & 0 \\
\hline \multirow[t]{3}{*}{ How satisfied with lab services } & Very satisfied & 2.2 & 30.3 \\
\hline & Satisfied & 92.1 & 69.7 \\
\hline & Unsatisfied & 5.8 & 0 \\
\hline
\end{tabular}

Patients were satisfied with the physical environments of the clinic i.e. cleanliness of the toilets and premises in general. Waiting benches/chairs were available but patients reported that there are days when the clinics were crowded and the benches were not sufficient to carter for all patients. At both clinics however, the majority of the participant complained of spending about six hours or more at the clinics for the services as indicated in table 5 .

Table 5: Patients' satisfaction with physical environment of the clinics and other variables assessed

\begin{tabular}{|c|c|c|c|}
\hline Main Variable & Specific variables & $\begin{array}{l}\text { Muhimbili } \\
\text { Hospital } n=190 \\
(\%)\end{array}$ & $\begin{array}{l}\text { Amana } \\
\text { Hospital } n=185 \\
(\%)\end{array}$ \\
\hline \multicolumn{4}{|c|}{ Cleanliness and appearance of the clinics. } \\
\hline & Good & 100 & 100 \\
\hline & Not good & 0 & 0 \\
\hline \multirow[t]{2}{*}{ Time spent at the clinic for services. } & More than 6 hours & 87.9 & 78.9 \\
\hline & Less than 6 hours & 12.1 & 21.1 \\
\hline \multicolumn{4}{|c|}{ Overall satisfaction with the clinic services } \\
\hline & Very satisfied & 1.1 & 44.3 \\
\hline & Satisfied & 94.7 & 55.7 \\
\hline & Unsatisfied & 4.2 & 0 \\
\hline
\end{tabular}

\section{Discussion}

Results of this study show that most of the respondents said the doctors were available at the clinics but they complained of long times spent waiting for consultation. Patient waiting time in outpatient clinics has been the major complaint. It has been shown that if patients wait less than 30 minutes usually they are satisfied. ${ }^{12}$ One of the reasons why patients had to wait for a long time is that there is a large number of HIV patients attending the clinics while few doctors are employed to provide the services. Lack of human resources has been shown to be an important obstacle affecting health care service provision ${ }^{11,13}$. 
The consultation time estimated by the majority of participants was about 10 to 15 minutes. This is similar to a study by Quintana et $\mathrm{l}^{10}$ where the average consultation time observed was 11 minutes and that of Anderson et $a 1^{14}$ where patients who spent 10 minutes or more with the doctor were satisfied. Results on privacy during consultation with the doctor and the dispenser indicate that Amana clinic is doing well as nearly all patients reported privacy while at $\mathrm{MNH}$ clinic majority of the respondents had no privacy. When providing services to the patient privavcy is necessary, since it makes the patient feel comfortable, ask questions, and understand easily the information given by the doctors, dispensers, and counselors. Lack of privacy contributed to patients being unsatisfied with the services. Similar results have been reported by other researchers. ${ }^{10.15}$

One of the predictors of satisfaction is the attitude of health workers. In our study the attitude of doctors, nurses, dispensers and laboratory technician was rated as being friendly and satisfying to the patient. However, at $\mathrm{MNH}$ clinic some of the participants said some health workers were unfriendly especially the dispensers (21.1\%). Our results are similar to those of Muhondwa ${ }^{16}$ who reported that at $\mathrm{MNH}$ patient were unsatisfied with negative attitudes of staff towards them. Regarding pharmacy services, drugs were available and the majority of patients were comfortable with the time spent waiting for the services (less than 30 minutes). However counseling of ARV side effects at MNH was not done properly. Similar results of patients being unsatisfied with the dispensing process have been reported by Marquez-Peiro et al ${ }^{17}$. Usually patients want patient care staff to explain about medications. Communicating with patients about medications especially on use and side effects has positive effects on their perceptions of pain and responsiveness, which is why it is correlated to overall patient satisfaction ${ }^{8}$. Regarding nurse and laboratory services, majority of the patients were satisfied, with only a few patients at MNH who were unsatisfied. The results of this study are similar to a study by Quintana ${ }^{8}$ which showed that the majority of the patients were satisfied with nurse and laboratory services.

The time of stay at the clinic was long most patients indicated spending more than five hours at the clinics, but this did not affect their satisfaction with the overall services at the clinics.

\section{Conclusion}

Most of the participants were satisfied with the services provided at the two clinics; however at $\mathrm{MNH}$ a few patients were unsatisfied. The study provides valuable information about the services delivered at the two clinics. Identified gaps in the delivery system of health care services, like lack of privacy during consultation with the doctor and dispensing of medicines at $\mathrm{MNH}$, and lack of proper medication counseling contributed to patients not being satisfied. Working to eliminate the identified gaps can improve service and fully satisfy patients.

\section{Acknowledgement}

We would like to thank Muhimbili national hospital and Amana Hospital for allowing us to carry out the study. We are also grateful to patients who agreed to participate in the study.

\section{References}

1. QAP Tanzania HIV Stigma Study Team. 2007. Evaluation of Knowledge, Attitudes and Practices of Health Care Providers toward HIV-positive Patients in Tanzania. Operations Research Results. Published for the U.S. Agency for International Development (USAID) by University Research Co., LLC, and Bethesda, MD.

2. National Bureau of Statistics [Tanzania] and Macro International Inc., 2006. Tanzania Service Provision Assessment Survey 2006: Key Findings on HIV/AIDS. Dar es Salaam, Tanzania: National Bureau of Statistics and Macro International Inc.

3. Mfinanga SG, Khawa A, Kimaro G, Kilale A, Kivuyo S, Senkoro M, et al. Patient's dissatisfaction with public and private laboratory services in conducting HIV related testing in Tanzania. Health services Research 2008; 8:167

4. Lyatuu MB Msamanga GI and Kalinga AK. Clients' satisfaction with services for prevention of mother- to-child transmission of HIV in Dodoma rural district. East African Journal of Public Health.2008; 5 (3):174-179

5. Sitzia J, Wood N. Patient satisfaction: A review of issues and concepts. Social Science \& Medicine 1997; 45(12):1829-1843.

6. Thiedke CC. What do we really know about Patient Satisfaction? Farm Pract Manag. 2007;14(1)33-36 
7. Muula AS, Chipeta J, Siziya S, Rudatsikira E, Mataya RH, Kataika E: Human resource requirements for highly active antiretroviral therapy scale-up in Malawi. BMC Health Services Research. 2007; 7:208.

8. Anderson RT, Camacho FT, Balkrishnan R Willing to wait? : The influence of patient wait time on satisfaction with primary care. $B M C$ Health service Research 2007; 7:31

9. Peter Tsasis, Christos Tsoukas, Gretty Deutsch. Evaluation of Patient Satisfaction in a Specialized HIV/AIDS Care Unit of a Major Hospital. AIDS Patient Care and STDs. 2002; 14(7); 347-349. doi:10.1089/108729100413211;

10. Muhondwa EPY, Leshabary MT, Mwangu M, Mbembati N, Ezekiel MJ. Patient Satisfaction at The Muhimbili National Hospital in Dar es Salaam Tanzania. East African Journal of Public bealth 2008; 5(2):67-73

11. Marquez-Peiro JF, Perez-Peiro C. Evaluation of Patient satisfaction in outpatient pharmacy. Farm Hosp.2008; 32(2):71-6

12. Huang XM. Patient attitude towards waiting in an outpatient clinic and its application. Health Serv Manage Res. 1994; 7(1) 2-8
13. Muula AS, Chipeta J, Siziya S, Rudatsikira E, Mataya RH, Kataika E: Human resource requirements for highly active antiretroviral therapy scale-up in Malawi. BMC Health Services Research. 2007; 7:208.

14. Anderson RT, Camacho FT, Balkrishnan R Willing to wait? : The influence of patient wait time on satisfaction with primary care. BMC Health service Research 2007; 7:31

15. Peter Tsasis, Christos Tsoukas, Gretty Deutsch. Evaluation of Patient Satisfaction in a Specialized HIV/AIDS Care Unit of a Major Hospital. AIDS Patient Care and STDs. 2002; 14(7); 347-349. doi:10.1089/ 108729100413211;

16. Muhondwa EPY, Leshabary MT, Mwangu M, Mbembati N, Ezekiel MJ. Patient Satisfaction at The Muhimbili National Hospital in Dar es Salaam Tanzania. East African Journal of Public bealth 2008; 5(2):67-73

17. Marquez-Peiro JF, Perez-Peiro C. Evaluation of Patient satisfaction in outpatient pharmacy. Farm Hosp.2008; 32(2):71-6 